\title{
Awareness, Knowledge, Attitude and Practice of Safety Occupants at Residential Houses in Libya
}

\author{
Mufida Mkharem, ${ }^{\mathrm{a}, \mathrm{b}, *}$ Nor Mariah Adam, ${ }^{\mathrm{a}}$ Eris Elianddy Supeni, ${ }^{\mathrm{b}}$ \\ ${ }^{a}$ Department of Mechanical and Manufacturing Engineering, Faculty of Engineering, Universiti Putra Malaysia, 43400 Serdang \\ ${ }^{b}$ Institute of Occupational Safety and Health, Tripoli, Libya \\ *Corresponding author: mufida_mln@yahoo.com
}

\begin{abstract}
Fire accidents are common accidents amongst residential house occupants in Libya. Some of the factors that can mitigate fire accidents in Libyan residential houses include fire safety awareness and knowledge. This study investigated the level of awareness and knowledge of fire safety amongst residential house occupants in Libya. The possibility and consequences of fire hazards and risk existing in residential houses in Libya were also studied. Experimental data obtained for $1.5 \mathrm{~m} / \mathrm{s}$ and $3.5 \mathrm{~m} / \mathrm{s}$ as walking and running evacuation time, respectively amongst residential house occupants in Libya were also compared. The sample consist of 90 respondents with instruments of fire safety awareness and knowledge, fire hazard and consequences, and the involvement of residential house occupants in fire emergency. Statistical analysis was performed at $p<0.05$ to determine the levels of residential awareness and knowledge regarding fire safety and the hazard and consequences. The findings illustrated that the items were highly reliable $(\alpha>0.7)$ and normally distributed. Also, the results illustrated that the majority of residential house occupants in Libya have fair level of fire safety awareness and knowledge with overall percentage of $80 \%$ and $90 \%$, respectively. On the other hand, the results further showed that majority of residential house occupants have good level of fire emergency involvement with 90\%. This paper proposes a fire safety assessment method which may form the basis of future fire safety practice in Libya.
\end{abstract}

Keywords - Awareness, Emergency, Evacuation time, Fire hazard, Fire safety, Knowledge, Libya

\subsection{INTRODUCTION}

The lives and properties of residential house occupants is often affected by fire accidents which could occur as a result of inadequate fire safety considerations in residential houses. In order to reduce the risk of live, injuries and property damages, the science of preventing and mitigating undesirable fire outbreak which is also known as fire safety must be embedded in residential buildings (Kobes et al. 2010, Ming Lo 1998, Lo et al. 2000). According to Leung and Chow (2016) fire accidents occur in residential buildings because of poor electrical wiring, problems with electric meter installation 
which could lead to leakage and overloads of electricity, lack of proper evacuation paths and exit routes and extreme combustibles building materials. These problems associated with most residential houses around the world constitute significant threat to live and properties, with more than 300,000 people killed by fire yearly (Jonsson et al. 2017). In fact, Xin and Huang (2013) stated that residential fires constitute about $39.7 \%$ of all building fires causing direct damage to properties worth about \$USD48,936,330, about 347 civilian injuries and 853 civilian deaths annually in China. Therefore, research on fire safety in residential houses becomes indispensable. Several solutions have been employed to mitigate the threat of fire in residential houses including the inclusion of building regulations, fire hazard education, fire intervention and regulation, building materials control and building designs amongst others (Xin and Huang 2013). However, research on fire safety in different countries is still desired.

Libya is in the northern part of Africa with a population of 6.5 million (Worldometers 2018). The majority of the people lives in the cities such as Tripoli, Benghazi, Misrata, Bayada, Zawiya, Zliten, Ajdabiya and so on. Nonetheless, with a current population growth rate of $1.58 \%$ (CIA World Fact 2018), a 50\% increase of the urban population is expected in the next three decades (Ali et al. 2017). Just like many developing countries, Libya has mapped out housing roadmaps in recent years in order to meet a fast-growing demand. This project has cost billions of Libyan diners with a view of a sustainable housing and urban improvement in Libya (Ali et al. 2017). However, various housing problems still exist. These problems have received little attention by the government owing to the country's political instability. Libya residential houses includes both modern designs found in cities and traditional houses mostly in the rural areas and old cities (Azlitni 2009). Traditional houses are mostly roofed with materials obtained from Date Palm Tree (El May et al. 2012). Due to low thermal resistivity and high flammability, these materials together with inadequate fire safety evacuation scheme has been reported to cause fire accidents in traditional Libyan residential houses (Agoudjil et al. 2011). On the other hand, most modern residential houses are prone to fire accidents due to lack of residential smoke alarms, deployable ladders, portable fire extinguishers, fire safety awareness and knowledge (Istre and Mallonee 2000, Shai 2006). In addition, most residential houses in Libya do not follow known safety standards (Mkharem et al. 2017). Inadequate power supply leading to the use of artificial light sources (e.g. candles) causes fire accident when in contact with combustible or highly flammable materials. Nevertheless, the most intricate cause of fire accidents are fire safety awareness and knowledge (Wolters et al. 2017). Individual behavior towards fire can help immensely in mitigating the threats of fire hazards in residential houses.

In recent years, fire safety has been studied in some countries with emphasis on risk factor (Xin and Huang 2013, Jonsson et al. 2017), fatality characteristics, fire alarms and response time (Sund and Jaldell 2018). However, there is no known study on the level of awareness and knowledge regarding fire safety amongst residential houses in Libya occupants. 
Therefore, the objective of this study is to (i) determine the level of awareness and knowledge regarding fire safety amongst residential houses occupants in Libya, (ii) identify the possibility of fire hazards and risks existing in the residential houses in Libya, and to determine their consequences (iii) Compare experimental data between evacuation time at $1.5 \mathrm{~m} / \mathrm{s}$ as walking and $3.5 \mathrm{~m} / \mathrm{s}$ as running amongst residential houses in Libya occupants.

\subsection{MATERIALS AND METHODOLOGY}

\subsection{Research Design}

Quantitative design was employed in this research. Random sampling methodology was used for data sampling which were based on different demographic backgrounds, fire safety awareness and knowledge, and fire emergency involvement of residential house occupants in Libya. The quantitative survey was designed and distributed to people living in the traditional and modern houses in Libya.

\subsection{Sample Size}

The collection of data through questionnaires was designed based on quantitative research approach. Adequate sampling method was needed to obtain the data desired for the study purpose and to obtain result that represents the whole population of the selected houses. Sample size determination was done by obtaining the total number of occupants of all residential houses. From a study, a researcher provides a simplified formula to calculate sample sizes. The formula used to calculate the sample sizes in this study can be seen in equation (1) (Yamane 1967). A 95\% confidence interval level for value of $p=0.05$ were assumed:

$$
S=\frac{N}{1+N(e)^{2}}=\frac{116}{1+116(0.05 e)^{2}}=90
$$

where $N$ was total number of population/population size, $e$ was level of precision $(p=0.05)$ and $S$ was the sample size per respondent.

The designed questionnaires were distributed to 90 respondents between July and August 2017. All the 90 respondents' data were then collected and analyzed using SPSS. Descriptive statistics analysis was used to determine the level of fire safety awareness and knowledge, and to identify the possibility of fire hazards and risks among residential house occupants in Libya. Geographical presentation such as histogram and bar charts were used to make the interpretation work easier. 


\subsection{Class interval}

The class interval in fire safety awareness and knowledge, fire hazard and consequences and fire emergency involvement amongst residential house occupants were determined. In this regard, the number of items and the score were used to calculate the maximum and minimum value as illustrates in equations (2) and (3).

$$
\begin{aligned}
& \text { Max }=10(\text { questions }) \times 5(\text { scores })=50 \\
& \text { Min }=10(\text { questions }) \times 1(\text { scores })=10
\end{aligned}
$$

Based on the study objectives, the classes were identified to be three classes which include poor, fair and good. The interval and the range of the poor, fair and good were calculated, see Table 1, while equation (4) was used for computing the interval.

$$
\text { interval }=\frac{\text { Max }- \text { Min }}{\text { Class }}=\frac{50-10}{3}=13.33
$$

Table 1: The Classes, Measurement and Interval Range

\begin{tabular}{lll}
\hline Class & Measurement & Range \\
\hline Poor & $10.00+13.33=23.33$ & $10.00-23.33$ \\
Fair & $23.33+13.33=36.66$ & $23.34-36.66$ \\
Good & $36.66+13.33=50.00$ & $36.66-50.00$ \\
\hline
\end{tabular}

\subsection{Instrumentations}

The main purpose of this study is to explore and determine the knowledge and awareness of fire safety amongst residential houses occupants in Libya. The survey questionnaire contained five main sections. Section one is about demographic information of the respondents which include; age, gender, highest level of study and job scope. Section two, three and four contained questions related to the level of fire safety awareness, knowledge, and fire emergency involvement amongst residential house occupants. The independent variables and their opinion on some issues regarding fire safety measures in their residential house using five Likert scale questionnaires; i.e. strongly disagree (1), disagree (2), neutral (3), agree (4), and strongly agree (5) (Nemoto and Beglar 2014). Section five includes fire hazard and consequences; this section discussed the opinion of the respondent living in the residential houses in Libya. The score description is shown as follow: Negligible (impose no harm at all to the occupants), Minor (may cause minor injuries to the occupants), Serious (may cause injuries to multiple occupants), Fatal (may cause death or critical wounds and injuries) and Catastrophic (may cause mass destruction and mass casualties). 


\subsection{RESULTS AND DISCUSSION}

3.1 Reliability Test

The sampling questions in the questionnaire used for data collection were tested for reliability using Cronbach's alpha as shown in Table 2. The results showed all the 40 items in the questionnaire were reliable with a Cronbach's alpha value greater than 0.7 . Alpha testing (values between $0-1$ ) has been used to statistically test the internal consistency among items in a questionnaire. The higher the alpha value the more reliable the questionnaire. Again, if the test items are closely related, the most likely the alpha score will be high (Dunn et al. 2014, Bonett and Wright 2015). Therefore, based in the alpha values, the test items can be said to be reliable.

Table 2: The Reliability Test Based on Cronbach's Alpha for the Variables Used to Assess Fire Safety Amongst Residential Occupants in Libya.

\begin{tabular}{llll}
\hline & $\begin{array}{l}\text { Cronbach's } \\
\text { Alpha }\end{array}$ & $\begin{array}{l}\text { Cronbach's Alpha Based on } \\
\text { Standardized Items }\end{array}$ & $\begin{array}{l}\text { N of } \\
\text { Items }\end{array}$ \\
\hline Awareness regarding fire safety & .764 & .766 & 10 \\
Knowledge regarding fire safety & .808 & .809 & 10 \\
Fire hazard and consequences & .645 & .633 & 10 \\
Involvement traditional house occupants in & .786 & .784 & 10 \\
fire emergency & .748 & .762 & 40 \\
All & & & 40 \\
\hline
\end{tabular}

3.2 Normality Test

Normality test was carried out to further statistically determine the significant of the sample data. The results are presented in Table 3 which shows that the data for fire safety awareness, and fire hazard and consequences were normally distributed as indicated by Kolmogorov-Sminov and Shapiro-Wilk test with $p$-values of .200 and .100 for awareness, and .180 and .123 for fire hazard and consequences, respectively. For example, the distribution curve for fire safety awareness can be seen in Fig. 1. The figure clearly demonstrated that the data for fire safety awareness were normally distributed. On the other hand, the data for fire safety knowledge and involvement of residential house occupants in fire emergency were shown not to be normally distributed with $p$-value less than 0.05 for Kolmogorov-Sminov (.004 and .000) and ShapiroWailk (.034 and .000), respectively. These results implies that the knowledge regarding fire safety and involvement of residential house occupants in fire emergency are significantly different from normal distribution, hence the data were subjected to centralization. 
Table 3: The Normality Test Based on Cronbach's Alpha for The Variables Used to Assess Fire Safety Amongst Residential Occupants in Libya.

\begin{tabular}{lllllll}
\hline & \multicolumn{2}{l}{ Kolmogorov-Smirnov } & \multicolumn{2}{l}{ Shapiro-Wilk } \\
\cline { 2 - 8 } & Statistic & Df & Sig. & Statistic & Df & Sig. \\
\hline Awareness regarding fire safety & .072 & 90 & $.200^{*}$ & .977 & 90 & .103 \\
Knowledge regarding fire safety & .116 & 90 & .004 & .970 & 90 & .034 \\
Involvement traditional house & .184 & 90 & .000 & .838 & 90 & .000 \\
Fire hazard and consequences & .082 & 90 & .180 & .978 & 90 & .128 \\
\hline
\end{tabular}

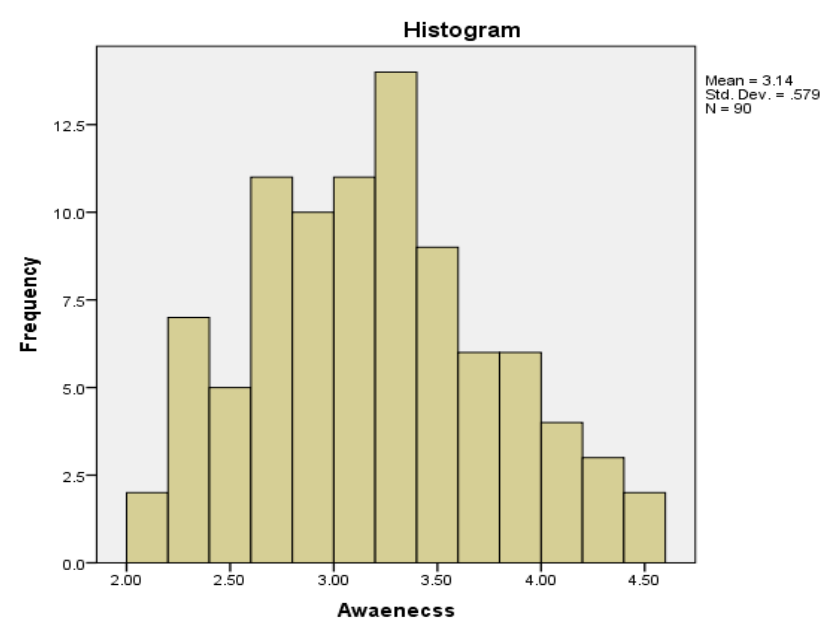

Figure 1: The data for fire safety awareness were normally distributed.

\subsection{Demographic Information}

The findings showed that 90 respondents $(n=90)$ participated in this research $(n=24)$ were male and $(n=66)$ were female. The majority of participants were between 11-20 years old and the minority were between the age of 51 years and above. The majority of these people hold bachelor's degree, followed by master's degree, then secondary school and the lowest were Diploma and Ph.D. holders. The majority of the participants have good educational background including lecturers and teachers, followed by people who are unemployed, then technicians and the lowest were from management.

\subsection{Awareness regarding fire safety}

The fire safety awareness amongst residential house occupants in Libya was determined by ten questions of the survey as shown in Table 4. For strongly disagree, the highest percentage was found in item two (31.11\%) which shows that majority of the respondents are not aware of the fire safety law. Furthermore, a large number of the respondents disagree (32.22\%) with item seven which states that "I memorize the building fire plan". Similarly, for neutral, the highest 
percentage was found in question seven (42.22\%). Meanwhile, $45.56 \%$ agreed with item ten which asked the respondent if they would leave their personal belonging during the evacuation. In addition, $34.33 \%$ strongly agreed with item ten, see Table 4.

Table 4: The Percentage Mean of Fire Safety Awareness Items Amongst All The Likert Scale.

\begin{tabular}{lllllll}
\hline $\mathbf{Q}$ & SD \% & $\mathbf{D} \%$ & $\mathbf{N} \%$ & $\mathbf{A} \%$ & $\mathbf{S A} \%$ & $\mathbf{T}$ \\
\hline 1 & 7.77 & 16.66 & 32.22 & 26.66 & 16.66 & 90 \\
2 & 31.11 & 22.22 & 33.33 & 12.22 & 1.11 & 90 \\
3 & 6.66 & 28.88 & 32.22 & 24.44 & 7.78 & 90 \\
4 & 3.33 & 26.66 & 40 & 23.33 & 6.66 & 90 \\
5 & 7.78 & 18.88 & 40 & 21.11 & 12.22 & 90 \\
6 & 8.89 & 20 & 34.44 & 32.22 & 4.44 & 90 \\
7 & 8.89 & 32.22 & 42.22 & 12.22 & 5.55 & 90 \\
8 & 6.66 & 14.44 & 40 & 33.33 & 5.55 & 90 \\
9 & 4.44 & 3.33 & 35.56 & 40 & 16.67 & 90 \\
10 & 4.44 & 2.22 & 13.33 & 45.56 & 34.33 & 90 \\
\hline
\end{tabular}

Fig. 2 illustrates the mean values for each survey items. From the figure, three regions were demarcated which include poor (0.00-2.33), fair (2.33-3.66) and good (3.66-5.00). Based on this separation, most of the mean values of the items were placed between 2.33 and 3.66 implying that they are fair. On the other hand, only one item each was placed between 0.00-2.33 and 3.66-5.00, for poor and good respectively.

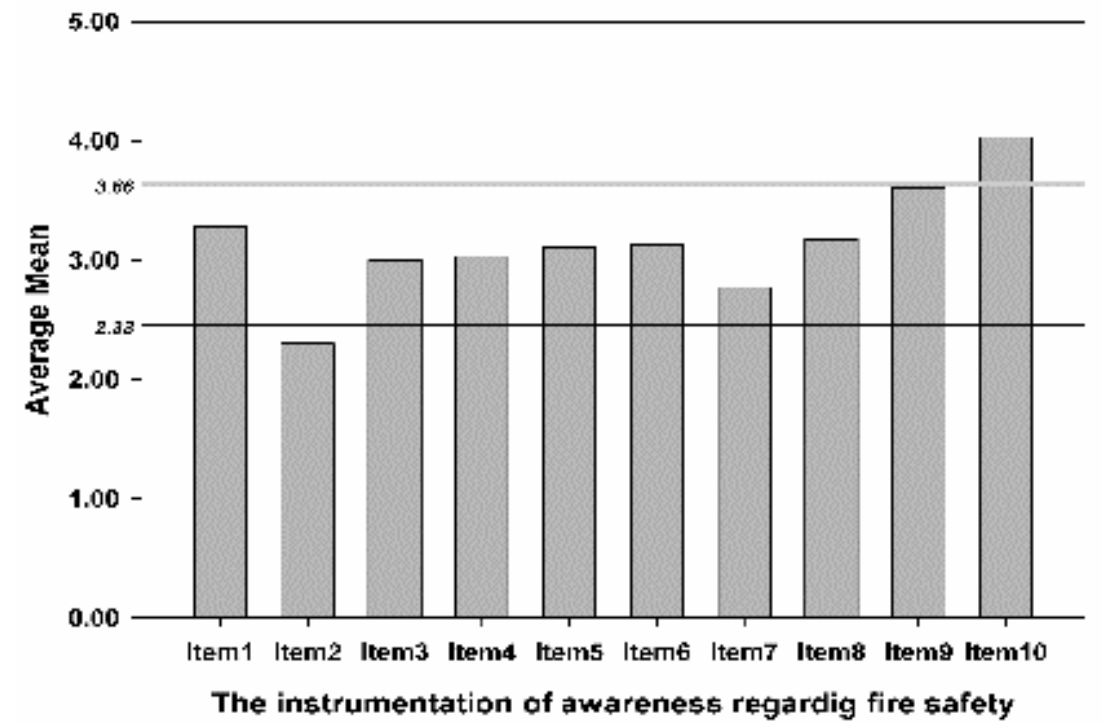

Figure 2: The average mean of fire safety awareness items. 
More so, Fig. 3 shows the distribution of the three groups of fire safety awareness amongst residential house occupants in Libya. From the figure, it can be seen that $80 \%$ of the total respondents were fair, while $10 \%$ of the respondents were found to be both poor and good, respectively. These results clearly signify that a large number of the residential house occupants in Libya are aware of some of the fire safety activities. However, some of the fire safety rules are not known to significant number of occupants, indicating a need for a more comprehensive fire safety awareness program for all residential houses in Libya.

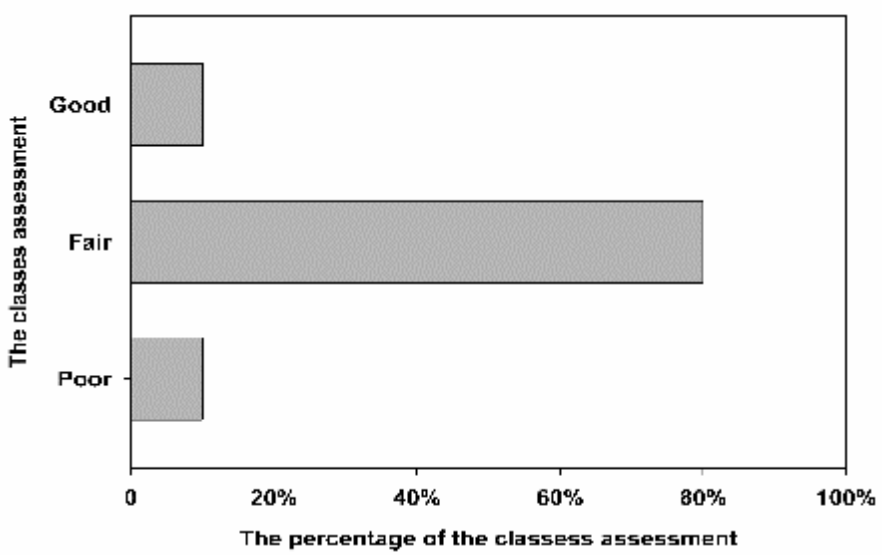

Figure 3: The classess assessment of fire safety awareness.

3.5 Knowledge regarding fire safety

The fire safety knowledge was evaluated using questioner survey based on ten items as shown in Table 5. For strongly disagree, the highest percentage $(25.56 \%)$ was found in an item one which asked about the participation in fire activities ("I have participated in fire drills before"). Similarly, for disagree, the highest result was found in an item one (46.67\%). For neutral, the highest percentage was found in an item eight (48.89\%) ("I know all the stages of fire development"). Also, the highest result for agree was found in an item eight (23.33\%). For strongly agree, the highest result was found in item five with $13.33 \%$, see Table 5 .

Table 5: The Percentage Mean of Fire Safety Knowledge Items Amongss all the Likert Scale.

\begin{tabular}{llllllll}
\hline Item & SD \% & D \% & N \% & A \% & SA \% & T & T \\
\hline 1 & 25.56 & 46.67 & 21.11 & 4.44 & 2.22 & 90 & \\
2 & 20.00 & 35.56 & 33.33 & 7.78 & 3.33 & 90 & \\
3 & 13.33 & 36.67 & 34.44 & 14.44 & 1.11 & 90 & \\
4 & 12.22 & 22.22 & 44.44 & 20 & 2.22 & 90 & \\
5 & 2.22 & 24.44 & 44.44 & 15.56 & 13.33 & 90 & \\
6 & 6.66 & 27.78 & 43.33 & 20 & 2.22 & 90 & \\
7 & 11.11 & 23.33 & 45.56 & 14.44 & 5.56 & 90 & \\
8 & 7.78 & 20 & 48.89 & 23.33 & 0 & 90 & \\
9 & 1.11 & 27.78 & 45.56 & 20 & 5.56 & 90 & \\
10 & 1.11 & 20 & 44.44 & 27.78 & 6.67 & 90 & \\
\hline
\end{tabular}


Fig. 4 illustrates the mean values for each survey items. From the figure, three regions were demarcated which include poor (0.00-2.33), fair (2.33-3.66) and good (3.66-5.00). Based on this separation, most of the mean values of the questions were placed between 2.33 and 3.66 which mean they are fair. Meanwhile, only one item was placed between $0.00-2.33$, which is poor.

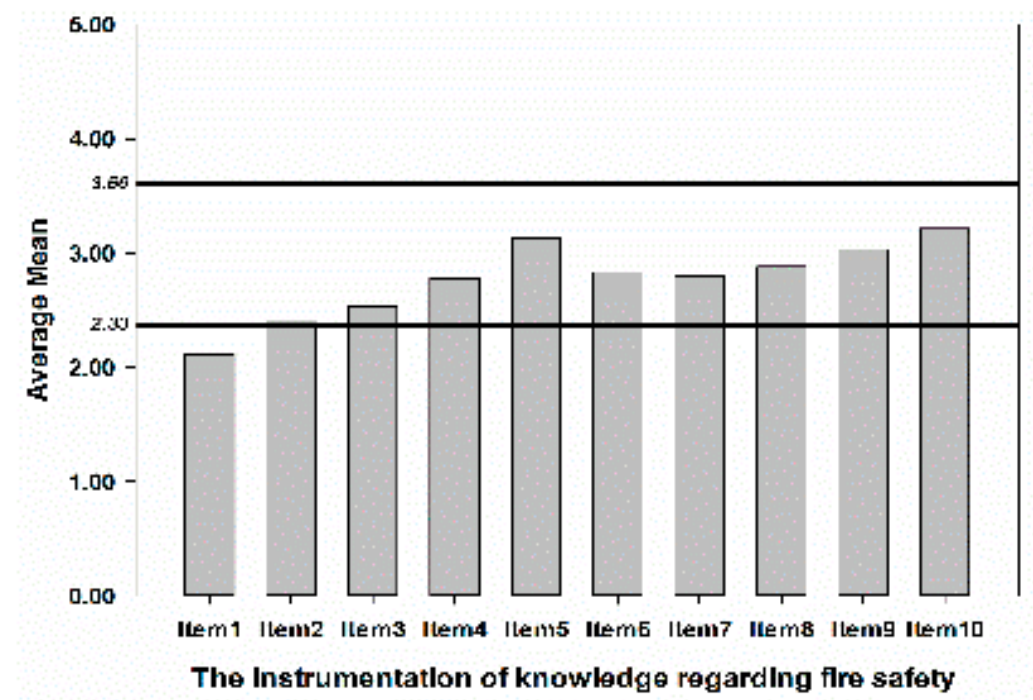

Figure 4: The average mean of fire safety knowledge items.

More so, the distribution of the three groups for fire safety knowledge amongst residential house occupants in Libya shows that $90 \%$ of the total respondents were fair. While $10 \%$ were found to be poor. Unlike fire safety awareness, the results of fire safety knowledge amongst residential house occupants in Libya indicate that a significant number of occupants have fair knowledge of fire safety activities. However, to improve fire safety knowledge amongst residential house occupants, more fire safety drills are required.

\subsection{Fire hazard and consequences}

To determined fire hazard and its consequences among residential house occupants in Libya, ten items from the survey were evaluated as can be seen in Table 6. For negligible ( $\mathrm{N} \%$ ), the highest percentage of $43.33 \%$ was found in item seven which asked if mattress, window curtains and carpets can sustain fire. For minor (M \%), the highest result was found in item two (38.89\%), which asked if hanging of clothes in the corridors could block escape route. For serious (S \%), the highest percentage was found in item one $(41.11 \%)$ which asked if poor corridor ventilation can trap smoke. For fatal (F $\%)$, the highest result was found in item five (50.00\%), which asked if dead end nearby corridor may cause confusion 
during fire evacuation. Meanwhile, for catastrophe $(\mathrm{C} \%)$, the highest result was found in question ten (17.78\%), with question asking if no proper fire action plan and emergency contact number was available, see Table 6.

Table 6: The Percentage Mean of Fire Hazard and Consequences Items Among all the Likert Scale

\begin{tabular}{lllllll}
\hline $\mathbf{Q}$ & $\mathbf{N}$ \% & $\mathbf{M}$ \% & $\mathbf{S} \%$ & $\mathbf{F} \%$ & $\mathbf{C} \%$ & $\mathbf{T}$ \\
\hline 1 & 20 & 8.89 & 41.11 & 25.56 & 4.44 & 90 \\
2 & 16.67 & 38.89 & 28.88 & 15.56 & 0 & 90 \\
3 & 13.33 & 23.33 & 22.22 & 40 & 1.11 & 90 \\
4 & 3.33 & 20 & 24.44 & 36.67 & 15.56 & 90 \\
5 & 14.44 & 14.44 & 21.11 & 50 & 0 & 90 \\
6 & 4.44 & 31.11 & 30 & 24.44 & 10 & 90 \\
7 & 43.33 & 3.33 & 15.56 & 37.77 & 2.22 & 90 \\
8 & 21.11 & 13.33 & 35.56 & 15.56 & 14.44 & 90 \\
9 & 12.22 & 23.33 & 27.78 & 21.11 & 15.56 & 90 \\
10 & 7.78 & 24.44 & 38.89 & 11.11 & 17.78 & 90 \\
\hline
\end{tabular}

Fig. 5 shows the mean values for each survey items. From the figure, three region were divided ranging from 0.00 2.33 for poor, 2.33-3.66 for fair and 3.66-5.00 for good. Based on this separation, all of the mean values of the questions were placed between 2.33 and 3.66 which mean they are fair. On the other hand, no single items were placed between 0.00 2.33 and 3.66-5.00. This indicates that no poor or good selection for fire hazard.

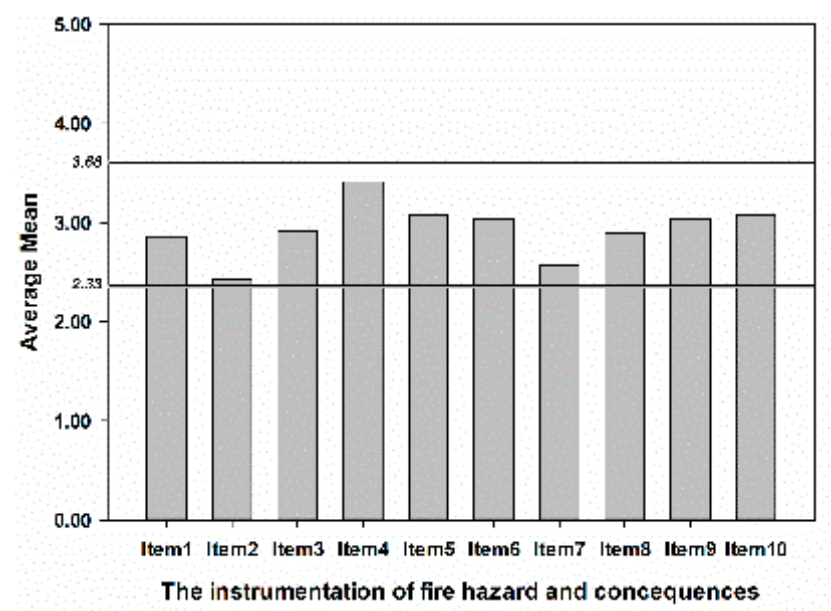

Figure 5: The average mean of fire hazard and consequences items.

Furthermore, the distribution of the three groups of knowledge regarding fire safety amongst residential house occupants in Libya. It is clear from the results that $100 \%$ of fire hazard and consequences are fair. Overall, the results of fire 
hazards and consequences have shown that the types of household properties and their location in residential house can significantly influence fire hazard. In addition, the ventilation system and access to exit doors during fire outbreak have been shown to significantly affect fire safety among residential house occupants in Libya. This calls for a review in the design of residential houses in Libya.

\subsection{Involvement of residential house occupants in fire emergency}

The Involvement of residential house occupants in fire emergency has been evaluated by ten survey items as shown in Table 7. For strongly disagree, the highest percentage $(10.00 \%)$ was found in item two which asked about fire emergency ("I believe the occupants should be involved in the fire emergency team if fire ever occurred"). Similarly, for disagree, the highest result was found in item two (23.33\%). For neutral, the highest percentage was found in item five of $37.78 \%$, which asked if safe evacuation procedure should be well known to all occupants. Also, the highest result was found in item three $(55.56 \%)$ for agree which states that "I believe occupants should be able to make fire risk assessment and evaluate fire hazards in the house". Meanwhile, for the strongly agree, the highest result was found from item seven with $60.00 \%$, which asked if saving lives is the main objective for fire emergency response plan, Table 7.

Table 7: The percentage mean of fire emergency involvement items among all the likert scale.

\begin{tabular}{lllllll}
\hline $\mathbf{Q}$ & SD \% & $\mathbf{D} \%$ & $\mathbf{N} \%$ & $\mathbf{A} \%$ & $\mathbf{S A} \%$ & $\mathbf{T}$ \\
\hline 1 & 5.56 & 18.89 & 24.44 & 28.89 & 22.22 & 90 \\
2 & 10 & 23.33 & 23.33 & 24.44 & 18.89 & 90 \\
3 & 6.67 & 0 & 6.67 & 55.56 & 31.11 & 90 \\
4 & 0 & 10 & 20 & 30 & 40 & 90 \\
5 & 8.89 & 12.22 & 37.78 & 22.22 & 18.89 & 90 \\
6 & 0 & 18.89 & 10 & 32.22 & 38.89 & 90 \\
7 & 0 & 0 & 10 & 30 & 60 & 90 \\
8 & 2.22 & 7.68 & 6.67 & 38.89 & 44.44 & 90 \\
9 & 0 & 5.56 & 16,67 & 31.11 & 44.44 & 90 \\
10 & 0 & 0 & 20 & 37.78 & 42.22 & 90 \\
\hline
\end{tabular}

Fig. 6 illustrates the mean values for each survey items. From the figure, three regions were demarcated including poor (0.00-2.33), fair (2.33-3.66) and good (3.66-5.00). Based on this separation, most of the mean values of the items were placed between 3.66 and 5.00 which mean they are good. From the other side, three mean values were placed between 2.333.66 which is fair, and no items placed in poor region. 


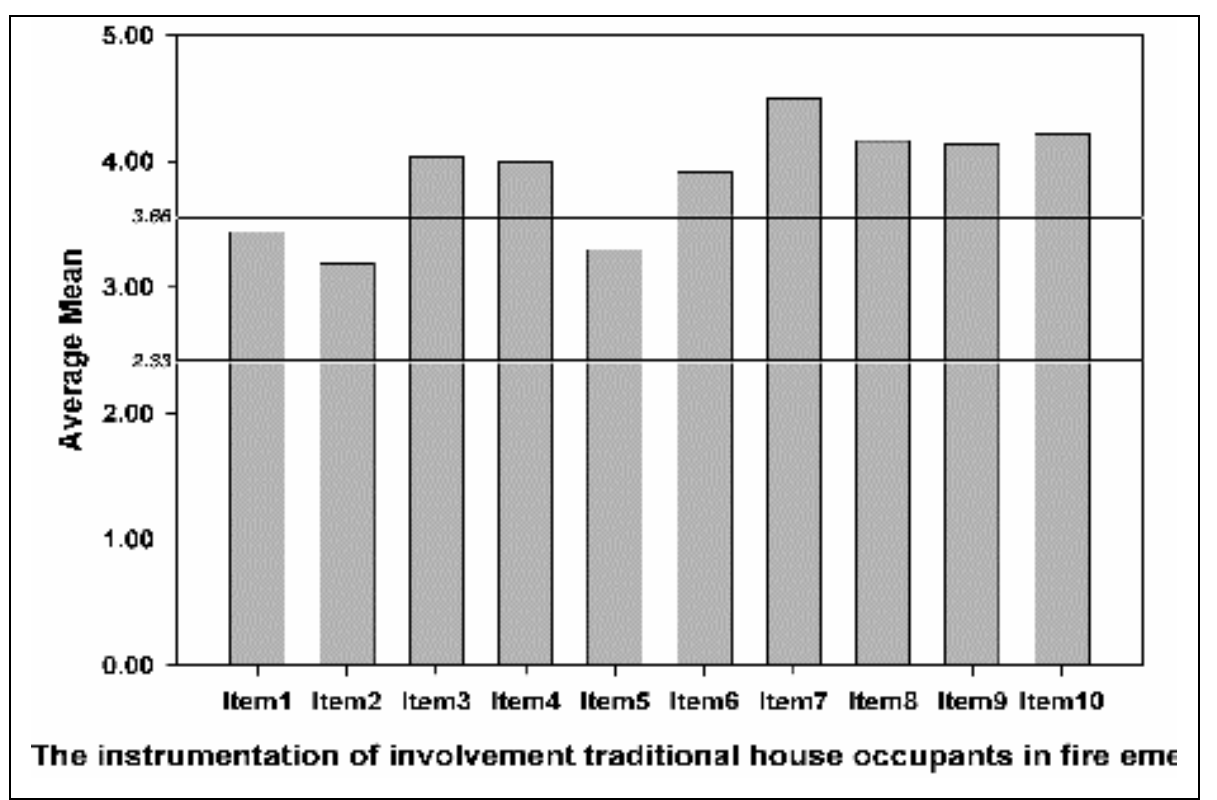

Figure 6: The average mean of fire emergency involvement items.

In addition, the distribution of the three groups of involvement traditional house occupants in fire emergency among residential house occupants in Libya shows that $70 \%$ of the total respondent have good fire emergency involvement, while $30 \%$ have fair involvement. Overall, the results of this study have shown that fire risk assessment and management are imperative for residential house occupants in Libya. Also, the results have shown that the most important fire emergency assessment is to save human lives. The residential occupants in Libya have shown to be willing to participate in fire safety drills and evacuation plans which would improve the country's fire safety strategies.

\subsection{Evacuation Time}

An evacuation drill was conducted at each residential house. A total of 90 residential are selected to be the experimental subjects. The participants were distributed to separate groups of three, each group was 30 residential with different numbers of people or residential houses as shown in Table 8. In order to make sure that they are all unfamiliar with the layout plan, they were not been briefed about current fire action plan and the assembly points where about. This is to test either they can find the way out and reach the assembly point within time. Table 8 shows the evacuation time for the evacuation drill by all the 90 participants on May 2017. For example, when walking with 5 persons the time was 17 secs while for 15 persons the time was $32 \mathrm{sec}$. Similarly, for group one, the running time was 12,15 and 19 secs for 5, 10 , and 15 persons, respectively. In the same vein, similar trends were found for group 2 and 3 when walking and running, respectively. These findings are in agreement with the results found from applying a fire drill in building in different faculties, institutes and labs in Universiti Putra Malaysia (Shazrizl 2016). Shazrizl (2016) found that any building with 4 
storey and below required 4 to 5 minutes of total evacuation time. While the time required for evacuation for any building of 4 to 8 storey is 8 minutes. The time for evacuation was taken from the moment of initiation of fire alarm system until the last person evacuated from the building to the nearest assembly point.

Table 8: Egress Evacuation and Pathfinder Analysis Comparison for Walking and Running Evacuation Speed of $1.5 \mathrm{~m} / \mathrm{Sec}$ and $3.5 \mathrm{~m} / \mathrm{Sec}$ for 5,10 and 15 Occupants.

\begin{tabular}{|c|c|c|c|c|c|c|c|}
\hline \multirow{4}{*}{$\begin{array}{l}\text { Residential } \\
\text { house }\end{array}$} & \multirow{4}{*}{$\begin{array}{l}\text { No. of } \\
\text { Participants }\end{array}$} & \multirow{2}{*}{\multicolumn{3}{|c|}{$\begin{array}{l}\text { Evacuation Time } \\
1.5 \mathrm{~m} / \mathrm{s} \text { (walk) }\end{array}$}} & \multirow{2}{*}{\multicolumn{3}{|c|}{$\begin{array}{l}\text { Evacuation Time } \\
3.5 \mathrm{~m} / \mathrm{s} \text { (running) }\end{array}$}} \\
\hline & & & & & & & \\
\hline & & & 10 & & & & 15 \\
\hline & & person & person & person & person & person & person \\
\hline Group 1 & 30 & 17 & 22 & 32 & 12 & 15 & 19 \\
\hline Group 2 & 30 & 19 & 24 & 34 & 13 & 16 & 21 \\
\hline Group 3 & 30 & 16 & 21 & 29 & 11 & 14 & 18 \\
\hline
\end{tabular}

\subsection{CONCLUSION}

This study attempts to determine the level of fire safety awareness and knowledge, fire hazard and consequences, and the fire emergency involvement amongst residential occupant in Libya. Survey questioner was applied, and the data was collected from 90 respondents. The items of the instrumentations were tested using reliability and normality tests. The results showed that the items were reliable with Cronbach's alpha $(\alpha>0.70)$. The fire safety assessment results have shown that the awareness and knowledge of residential house occupants in Libya were fair with $80 \%$ and $90 \%$, respectively. While the fire emergency involvement was shown to be good with almost $90 \%$. The analysis of fire safety undertaken also extended our knowledge of the importance of training people to involve in fire emergency programs. Despite its exploratory nature, this study offers some insight into fire safety assessment amongst the residential occupant in Libya. The findings of this study have a number of important implications for future practice and policy making regarding fire safety in Libya.

\section{REFERENCES}

Agoudjil, Boudjemaa, Adel Benchabane, Abderrahim Boudenne, Laurent Ibos, and Magali Fois. (2011). Renewable materials to reduce building heat loss: Characterization of date palm wood. Energy and buildings 43 (2-3):491497. 
Ali, Osama Kh, Noorazuan Hashim, Katiman Rostam, and Hamzah Jusoh. (2017). Changes in residential land-use of Tripoli city, Libya: 1969-2005. Geografia-Malaysian Journal of Society and Space 4 (1).

Azlitni, B. (2009). The Libyan Architectural Features between Tradition and Modernization. International Journal for Housing Science and Its Applications 33 (3):137.

Bonett, Douglas G, and Thomas A Wright. (2015). Cronbach's alpha reliability: Interval estimation, hypothesis testing, and sample size planning. Journal of Organizational Behavior 36 (1):3-15.

CIA World Fact. (2018). "World Fact Book." accessed March. https://www.cia.gov/index.html.

Dunn, Thomas J, Thom Baguley, and Vivienne Brunsden. (2014). From alpha to omega: A practical solution to the pervasive problem of internal consistency estimation. British Journal of Psychology 105 (3):399-412.

El May, Yassine, Sophie Dorge, Mejdi Jeguirim, Gwénaelle Trouvé, and Rachid Said. (2012). Measurement of gaseous and particulate pollutants during combustion of date palm wastes for energy recovery. Aerosol and Air Quality Research $12(5): 814-825$.

Istre, Gregory R, and Sue Mallonee. (2000). Smoke alarms and prevention of house-fire-related deaths and injuries. Western journal of medicine 173 (2):92.

Jonsson, Anders, Carl Bonander, Finn Nilson, and Fredrik Huss. (2017). The state of the residential fire fatality problem in Sweden: epidemiology, risk factors, and event typologies. Journal of safety research 62:89-100.

Kobes, Margrethe, Ira Helsloot, Bauke De Vries, and Jos G Post. (2010). Building safety and human behaviour in fire: A literature review. Fire Safety Journal 45 (1):1-11.

Leung, KK, and Cheuk Lun Chow. (2016). "A brief discussion on fire safety issues of subdivided housing units in Hong Kong." 3rd Residential Building Design and Construction (RBDC) Conference.

Lo, SM, KC Lam, and Richard KK Yuen. (2000). Views of building surveyors and building services engineers on priority setting of fire safety attributes for building maintenance. Facilities 18 (13/14):513-523.

Ming Lo, Siu. (1998). A building safety inspection system for fire safety issues in existing buildings. Structural Survey 16 (4):209-217.

Mkharem, M, NM Adam, EE Supeni, and S Mustapha. (2017). Fire severity prediction analysis of a traditional libya house roofing materials: A case study. JOURNAL OF MECHANICAL ENGINEERING AND SCIENCES 11 (3):29522966.

Nemoto, Tomoko, and David Beglar. (2014). "Likert-scale questionnaires." JALT 2013 Conference Proceedings.

Shai, Donna. (2006). Income, housing, and fire injuries: a census tract analysis. Public health reports 121 (2):149-154. 
Shazrizl, bin Z. (2016). "The study of fire safety at residential colleges in Universiti Putra Malaysia, Serdang." Master, Universiti Putra Malaysia.

Sund, Björn, and Henrik Jaldell. (2018). Security officers responding to residential fire alarms: Estimating the effect on survival and property damage. Fire Safety Journal 97:1-11.

Wolters, Erika Allen, Brent S Steel, Daniel Weston, and Mark Brunson. (2017). Determinants of residential Firewise behaviors in Central Oregon. The Social Science Journal 54 (2):168-178.

Worldometers. (2018). "Sociedade e Meios de Comunicaca o." accessed March. http://www.worldometers.info/pt/.

Xin, Jing, and Chongfu Huang. (2013). Fire risk analysis of residential buildings based on scenario clusters and its application in fire risk management. Fire Safety Journal 62:72-78.

Yamane, Taro. (1967). Elementary sampling theory. 